\title{
EVALUATION OF THE SEISMIC BEHAVIOR OF THIN REINFORCED CONCRETE SHEAR WALL INVIGORATED WITH FRP YARN UNDER LATERAL FORCE
}

\author{
Majid Reza Heydari Zadeh \\ Department Of Civil Engineering, Qeshm Branch, Islamic Azad University, Qeshm, Iran \\ Yousef Zandi \\ Member Of Academic Staff, Department Of Civil Engineering,Tabriz Branch, Islamic Azad University \\ Tabriz, Iran
}

\begin{abstract}
In this article we studied the non-linear behavior of reinforced and non-reinforced concrete shear wall considering the real stress-strain curves of the concrete, steel and FRP in a three-dimensional way by use of limited elements method. For using the limited components method, by use of ABAQUS software, the reinforced and non-reinforced concrete shear walls were modeled in a three dimensional way and were exposed under lateral loads, and the fraction pattern and destruction mechanisms in the original wall were reinforced by the reinforcement method such as use of FRP materials and at this stage the response of the reinforced wall was compared with the functioning of the original one, and the extent of the effect of using the reinforcement method against the lateral loads was determined. At last, we can conclude that the reinforced concrete shear wall with FRP materials has a better functioning than other reinforcement methods. In addition, use of CFRP screens has less final displacements compared with AFRP and GFRP screens.
\end{abstract}

Keywords: reinforced concrete shear wall, lateral loads, fraction pattern, limited element, FRP reinforcement

\section{INTRODUCTION}

Many of the existing constructs are vulnerable against the effects of various loads and thus their resistance against these loads should be elevated. The destruction caused by the effects of earthquake force to the reinforced concrete construct is a progressive one. Considering the mentioned conditions, safety of the constructive components against the effects of lateral loads has a significant importance. Especially regarding the constructs that are situated in specific positions. For increasing the resistance against lateral loads there are various conventional ways among the most important of them we can mention the use of local reinforcement like steel and concrete veneers for the constructive components and also adding new constructs like a compound steel shear wall. The defects of these ways are that firstly, they impose great gravity loads to the construct and finally the foundation, and secondly, they require much time for installment, thus, they are not economically advisable. An effective and also economic way for this purpose is use of FRP screens for reinforcement. FRP composites have been used for 50 years in construct engineering in areas of construction, reinforcement, invigoration, restoration and optimization of the existing constructs. During recent decades, there were great advances in use of FRP materials, which are an advanced type of composites. FRP materials are composite materials including yarn with high resistance that are situated in a polymeric ground. The yarn in a FRP composite is the main porter member and have high resistance as long as they are in strain. FRP composites today are mentioned as a good replacement for steel due to their high resistance, durability against fraction and the ease of their portage and installment. Many composites have very high resistance against fatigue. Unlike steel, FRP composites don't undergo gradual softness or decrease in hardness before any fraction against the coming and going loads. As a very important advantage and unlike steel, FRP composites have a high resistance 
against corrosion. These materials due to various thermal extension ratio in two cases of same direction with yarn and vertical to the yarn, act orthotropic under the thermal loading as well, and thus they are not ruined by the thermal strains. However, in materials like steel, due to their isotropic quality, due to thermal stress much severe destruction could occur. These materials can easily adapt with the environment and operate properly. In addition, use of these materials by increasing the resistance of the construct can result in considerable elevation of the construct's ability in confronting the lateral forces. In this research we examined the behavior of the reinforced and non-reinforced concrete shear wall regarding the real stress-strain curves of concrete, steel and FRP by use of the limited element method.

\section{LITERATURE STUDY DEFINITION OF FRP}

Composite yarn is material that has high resistance against strains. In industry these yarn are not usually used solely, but in combination with resin and matrixes. FRP, which stands for Fiber Reinforced Polymer is a type of composite composed of two fiber parts, or supportive yarn that are surrounded by a resin matrix made from polymer.

\section{REINFORCED CONCRETE SHEAR WALL INVIGORATED WITH FRP MATERIALS}

FRP materials are composites including yarn with high resistance in a polymeric ground. Yarn in FRP composite is the main porter member and have high hardness and resistance as long as in strain.

\section{USE OF FRP MATERIALS IN REINFORCEMENT OF CONCRETE SHEAR WALL}

Studies have shown that use of composite materials is effective in obviating the weakness of walls. The compounding process is done by sticking FRP screens to the border elements. For understanding the effects of FRP screens on the reinforced concrete shear wall, CFRP screens were imposed in various ways to the reinforced concrete walls and separately the behavior of load and displacement were studied.

\section{METHODS}

In this research, we studied the behavior of reinforced and non-reinforced concrete shear walls considering the real stress-strain curves of eth concrete, steel and FRP screens by use of limited element method. For using this method, by use of ABAQUS software the reinforced and non-reinforced concrete shear walls were modeled in a three-dimensional way and until reaching their final capacity, were exposed to lateral loads. The modeling of the samples was done by using a series of specific elements that their behavior is similar or close to the behavior of concrete, steel and FRP. In modeling with ABAQUS, the FRP element was a S4R type and the concrete element was C3D8R. for this purpose, a number of reinforced concrete shear walls that their experimental results are existing in the technical literature, were selected and after numeric analysis, the getting up curves, destruction pattern and fraction mechanisms were compared with experimental results.

\section{REINFORCED CONCRETE SHEAR WALL}

The geometric features of this wall include a height of 3.6 meters, width of 1.2 meters and thickness of 0.1 meters. The features of the concrete materials used in the shear wall are:

Table 1. Features of the concrete materials in the wall

\begin{tabular}{|c|c|c|c|c|c|}
\hline$f_{r}(\mathrm{MPa})$ & $f_{t}(\mathrm{MPa})$ & $E_{c}(\mathrm{GPa})$ & $v$ & $\begin{array}{l}\gamma_{c}(k g \\
\left./ m^{3}\right)\end{array}$ & $f_{c}(\mathrm{MPa})$ \\
\hline $\begin{array}{r}\text { Concrete's } \\
\text { disposition } \\
\text { model }\end{array}$ & $\begin{array}{r}\text { Concrete's } \\
\text { strain } \\
\text { model }\end{array}$ & $\begin{array}{r}\text { Concrete's } \\
\text { elasticity } \\
\text { model }\end{array}$ & $\begin{array}{r}\text { Poison } \\
\text { ratio }\end{array}$ & $\begin{array}{l}\text { Specific } \\
\text { weight of } \\
\text { concrete }\end{array}$ & $\begin{array}{r}28 \text {-day } \\
\text { resistance } \\
\text { of concrete }\end{array}$ \\
\hline
\end{tabular}


The Turkish Online Journal of Design, Art and Communication - TOJDAC August 2016 Special Edition

$\begin{array}{cccr}3.94 & 24.04 & 6.31 & \begin{array}{r}\text { Wall } \\ \text { sample }\end{array} \\ E_{c}=5000 \sqrt{f_{c}}=28.1 \mathrm{GPa} & 1 \text { equation } & \text { 2 equation } & \\ f_{t}=0.54 \sqrt{f_{c}}=3.04 \mathrm{MPa} & & 3 \text { equation } \\ f_{r}=0.7 \sqrt{f_{c}}=3.94 \mathrm{MPa} & \end{array}$

\section{LONGITUDINAL AND LATITUDINAL FITTINGS IN THE SHEAR WALL}

The longitudinal fitting used in the concrete sample has a $10 \mathrm{~mm}$ diameter and the latitudinal fitting has a $6 \mathrm{~mm}$ diameter. The features of the steel materials used in this wall are as following:

Table 2. Features of the steel materials of the fitting

\begin{tabular}{rrrrrr}
\multicolumn{2}{c}{$\sigma_{t}(\mathrm{MPa})$} \\
$\begin{array}{r}\text { Stress of } \\
\text { steel flow }\end{array}$ & $\begin{array}{c}\varepsilon_{t} \\
\text { Strain of flow }\end{array}$ & Poison ratio & $\begin{array}{r}\mathrm{E}(\mathrm{GPa}) \\
\text { Steel's } \\
\text { elasticity } \\
\text { model }\end{array}$ & $\begin{array}{r}\gamma\left(\mathrm{kg} / \mathrm{m}^{3}\right) \\
\text { specific }\end{array}$ & \\
weight $\begin{array}{r}\text { of } \\
\text { steel }\end{array}$ & \\
\hline \hline 420 & 108.0 & 3.0 & 210 & 7850 & fitting
\end{tabular}

\section{EXAMINATION OF THE BORDER CONDITIONS OF THE EXPERIMENTAL TEST}

The type of analysis used for solving this issue is a cyclic analysis that is entered to the upper part of the wall in an incoming and outgoing way. The backrest conditions of the shear wall is in a way that the lower part of the wall that is the foundation is supposed as completely tangly, the entered loads to the wall unlike the simplicity in the construction and designing of these concrete walls, the real response of the members is somehow complex. The general behavior of walls is a combination of shear bending and axial responses. The sections of the wall are exposed to pressure axial forces caused by gravity loads of the bottom and their own weight. The operating axial pressure on the wall is calculated up to $10 \%$ by the multiplication of the pressure resistance of the concrete on the shear wall surface. Loads that are entered to the wall are a lateral type in form of movement by a hydraulic lever in an incoming and outgoing horizontal load, the extent of which is 556 kilo-newton and a pressure load that is entered vertically to the wall with an extent of 379.2 kilo/newton. The meshing of the concrete wall has dimensions of $10 * 10 \mathrm{~cm}$ and the whole wall has 816 elements that are C3D8R type. We may interpret the C3D8R element as a forthcoming one. The first letter of it is $\mathrm{C}$ standing for Continuum, 3D means three-dimensional element, 8 is the number of element knots and R means reduced integral, and in this state the number of points for calculating integrals has reduced. The meshing of the used fittings has dimensions of $20 \mathrm{~cm}$ and all fittings inside the wall are 1174 elements that are T3D2 type. T stands for Truss, 3D means threedimensional element and 2 is the number of the elements knots.

\section{FINDINGS OF THE STUDY}

In this part, we first examine a number of FRP samples with various patterns and then we draw the loading and displacement diagrams in order to compare them with one another. 
Problem no.1: reinforcement of the concrete shear wall by use of FRP materials in a local way

The shear wall used in this study was added to the mentioned reinforced concrete shear wall with FRP materials as the reinforcement method. The geometric and dimensional features of FRP materials are in a way that they can cover the destructions caused by strains and pressure to the wall in the upper and lower sections completely. In addition, the thickness of this FRP layer is $9 \mathrm{~mm}$. the meshing of FRP materials has a $10 * 10 \mathrm{~cm}$ dimension and the whole FRP has 624 elements that are S4R. S stands for normal layer element for analysis of stress-strain, 4 is the number of knots and $\mathrm{R}$ means reduced integral in which the number of points for calculating integral has decreased. The features of the FRP materials used in this shear wall are in table 1.

Table 3. the features of FRP materials

\begin{tabular}{|c|c|c|c|c|}
\hline $\begin{array}{r}\sigma_{t}(\mathrm{MPa}) \\
\text { resistance } \\
\text { final strain }\end{array}$ & $\begin{array}{c}\varepsilon_{t} \\
\text { final strain }\end{array}$ & poison ratio & $\begin{array}{r}\mathrm{E}(\mathrm{GPa}) \\
\text { model } \\
\text { elasticity } \\
\text { FRP }\end{array}$ & $\begin{array}{l}\quad \gamma\left(\frac{k g}{m^{3}}\right) \\
\text { specific } \\
\text { FRP weight }\end{array}$ \\
\hline 3200 & 25.0 & 3.0 & 420 & 1200 \\
\hline
\end{tabular}

The dimensional features of this FRP are $1.2 \mathrm{~m}$ length, $1.2 \mathrm{~m}$ width and $9 \mathrm{~mm}$ thickness, which in 1.3 and 2.3 they have covered the length of the wall. In figures () the form and meshing of the FRPs is seen.

The type of analysis used is cyclic that is done in an incoming and outgoing way to the upper part of the wall. The backrest condition is that the lower part of the wall, which is the foundation, is supposed as completely tangly. The loads entered to the wall despite simplicity in the construction and designing, the general behavior of the walls is a combination of shear bending and axial responses. The sections of the wall are exposed to operating axial pressures on the wall and up to $10 \%$ are the multiplication of the pressure resistance of the concrete on the surface of the wall. . Loads that are entered to the wall are a lateral type in form of movement by a hydraulic lever in an incoming and outgoing horizontal load, the extent of which is 556 kilo-newton and a pressure load that is entered vertically to the wall with an extent of $379.2 \mathrm{kilo} /$ newton.

The results of the reinforcement of the shear wall by use of FRP materials in a local way

As expected from the functioning of the shear wall under lateral loads with FRP materials the portage increased and also there was little change in the formability of the wall and the reduction of the tension in longitudinal fittings, but the main defect of this reinforcement method is that the upper and lower part of the wall that are covered with FRP are intact and resistant against the pressure and strain forces, but the middle part of the reinforced concrete that is not invigorated caused that all pressures and straining forces enter to that area and the destruction mechanism takes place there. As seen in diagram 1, the portage capacity of the shear wall is reinforced by $14.4 \%$ and due to this increase, the formability of the shear wall changes from 3.3 to 3.5 .

Problem no.2: reinforcement of the reinforced concrete shear wall by use of FRP materials in a plaid pattern

As expected from the functioning of the shear wall under lateral loads with FRP materials the portage increased and also there was little change in the formability of the wall and the reduction of the tension in longitudinal fittings, and the defect occurring in problem 1 doesn't occur here. As seen in diagram 1, the portage capacity of the reinforced shear wall increases by $26 \%$, and due to this increase, the formability of the wall changes from 3.3 to 3.88 . 
Problem no.3: reinforcement of the reinforced concrete shear wall by use of FRP materials in a one-way diagonal from left

As expected from the functioning of the shear wall under lateral loads with FRP materials the portage increased and also there was little change in the formability of the wall and the reduction of the tension in longitudinal fittings, but the main defect of this way is that the direction of FRP is against the straining fractions, thus, its effect of reinforcement on the wall is not considerable. As seen in diagram 1, the portage capacity of the shear wall is increased by $11.3 \%$ and due to this increase, the formability of the wall changes from 3.3 to 3.45 .

Problem no.4: reinforcement of the reinforced concrete shear wall by use of FRP materials in a one-way diagonal from right

As expected from the functioning of the shear wall under lateral loads with FRP materials the portage increased and also there was little change in the formability of the wall and the reduction of the tension in longitudinal and latitudinal fittings, and the defect occurring in previous problem is obviated, since the direction of FRP is same as straining fractions and we observe a better behavior by the wall. As seen in diagram 1, the portage capacity of the shear wall is increased by $17.8 \%$ and due to this increase, the formability of the wall changes from 3.3 to 3.63 .

Results gained from reinforcement of the shear wall by FRP materials in a one-way diagonal from right

Problem no.5: reinforcement of the reinforced concrete shear wall by use of FRP materials in a cross way

As expected from the functioning of the shear wall under lateral loads with FRP materials the portage increased and also there was little change in the formability of the wall and the reduction of the tension in longitudinal and latitudinal fittings, and as we see the behavior of this shear wall is better than the other two problems, since the direction of FRP is same as pressure and straining fractions. As seen in diagram 1 , the portage capacity of the shear wall is increased by $22.6 \%$ and due to this increase, the formability of the wall is changed from 3.3 to 3.75 .

Problem no.6: reinforcement of the reinforced concrete shear wall by use of FRP materials in a full way

As expected from the functioning of the shear wall under lateral loads with FRP materials the portage increased and also there was little change in the formability of the wall and the reduction of the tension in longitudinal and latitudinal fittings, and the main defect in the local reinforcement doesn't occur here, and the destructions caused by the strain and pressure are gone, since the whole reinforced concrete shear wall is surrounded by FRP fully. In the below figures the contour of the tension and displacement within the wall's length could be seen. As seen in diagram 1, the portage capacity of the shear wall is increased by $28.8 \%$ and due to this increase, the formability of the shear wall increases from 3.3 to 3.95 .

COMPARISON OF THE FORCE-DISPLACEMENT DIAGRAM IN THE 6 CASES OF STUDY

Now we can draw the 6 studied cases in one diagram and observe the extent of increase of the portage capacity and changes of displacement and formability of the reinforced concrete shear wall. 


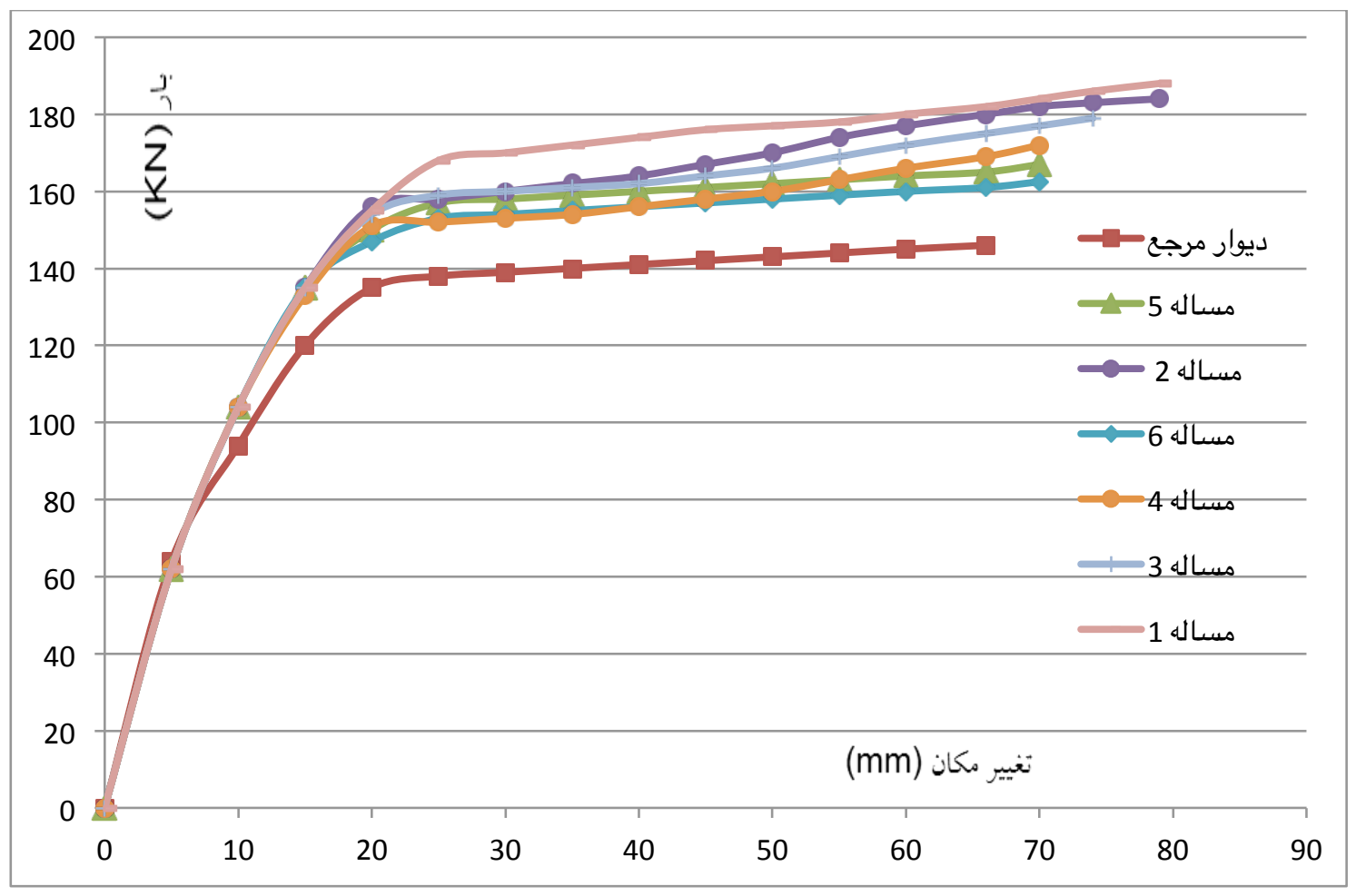

Diagram 1. Comparison of 6 force-displacement diagrams of the wall for the 6 cases of study

In the below table we can see the extent of final load, final displacement and the formability of each shear wall under the effect of reinforcement by FRP materials. As seen in the below table, the highest portage capacity and formability occur in the $6^{\text {th }}$ case.

Table 4. Results of the final load, displacement and formability of the shear wall

\begin{tabular}{|r|r|r|r}
\hline $\begin{array}{r}\text { Formability of the } \\
\text { shear wall }\end{array}$ & $\left.\begin{array}{r}\text { Final } \\
\begin{array}{r}\text { displacement } \\
(\mathbf{m m})\end{array}\end{array}\right)$ Final load (KN) & Sample \\
\hline 3.3 & 66 & 146 & Original wall \\
\hline 5.3 & 70 & 167 & Problem no.1 \\
\hline 88.3 & 5.77 & 184 & Problem no.2 \\
\hline 45.3 & 69 & 5.162 & Problem no.3 \\
\hline 63.3 & 5.72 & 172 & Problem no.4 \\
\hline 75.3 & 75 & 179 & Problem no.5 \\
\hline 95.3 & 79 & 188 & Problem no.6 \\
\hline
\end{tabular}

\section{CONCLUSION}

Non-linear analyses offer a strong tool for prediction of the behavior of reinforced concrete shear wall. These studies caused essential changes in the instructions and methods of designing concrete elements. The passing of time, constructive damages and weakness of old instructions have caused the improper functioning of existing constructs against earthquakes. On the other hand, in recent years composite materials have gained many applications in reinforcement of constructive elements. Top features of these materials have led them to the first options in reinforcement projects. However, a review of previous studies shows there has been no experimental test or analysis on the reinforcement of concrete thin shear 
wall by FRP materials. The evaluation of the seismic behavior of the reinforced concrete thin shear wall by FRP materials under lateral loads resulted in the following items:

- $\quad$ In examining the effect of lateral loads on the reinforced concrete shear wall considering the nonlinear geometric effects and materials simultaneously is necessary.

- $\quad$ The extent of the energy of lateral loads and their place of impact has a significant effect on the response of the reinforced concrete shear wall.

- $\quad$ Considering the direction of the effect of lateral loads in the area of the concrete construct that is exposed to the effect of strain, we require a higher level of reinforcement compared with the pressure area.

Use of experimental tests besides confirming the authenticity of this modeling can be also useful in detection of defects and potential inaccuracies.

- $\quad$ Reinforcement by FRP materials has significant effects on the functioning of the construct's behavior against lateral loads and can reduce the maximum displacement that is the sign of destruction and tension in the fittings inside the concrete.

- $\quad$ By reinforcement of the concrete shear wall by FRP materials in a full way, the portage capacity of the wall increases by $28.8 \%$ and due to this increase, the formability of the shear wall would also increase by $20 \%$ and there would be an optimal functioning under the effect of lateral forces.

- $\quad$ As we see when the yarn of the FRP tapes are in direction of longitudinal armatures, the behavior of the shear wall would improve against the lateral loads and would gain an optimal functioning.

- Use of CFRP screens has a less final displacement compared with GFRP and AFRP screens. This is due to the less final resistance and thus, the final strain of CFRP compared with GFRP. Thus, depending on the type and place of reinforcement, we can use polymeric screens made from glass or carbon.

\section{REFERENCES}

Hesari amin mohamad, sardari hatef, lotfolahy yaghin mohamad Ali/2008/modeling and analysis with ABAQUS software/foruzesh publications

Mostofinejad, D. and Maryam, M., "Effect of confining of boundary elements of slender RC shear wall by FRP composites and stirrups" Engineering Structures 41, (2012), 1-13. 